Article

\title{
Flood Inundation Modelling of Flash Floods in Steep River Basins and Catchments
}

\author{
Davor Kvočka * (D), Reza Ahmadian (D) and Roger A. Falconer \\ Hydro-environmental Research Centre, School of Engineering, Cardiff University, Cardiff CF24 3AA, UK; \\ ahmadianr@cardiff.ac.uk (R.A.); falconerra@cardiff.ac.uk (R.A.F.) \\ * Correspondence: kvockad@cf.ac.uk
}

Received: 31 July 2017; Accepted: 12 September 2017; Published: 15 September 2017

\begin{abstract}
The potential flood inundation extent can be estimated with flood inundation models, which can differ in the level of physical and numerical modelling complexity included in the solution procedure. In recent years, several studies have highlighted the benefits of shock-capturing flood inundation models, particularly when modelling a high Froude number or supercritical flows, or in areas prone to the occurrence of rapidly varying flood events, such as flash floods. Nonetheless, decision makers are often reluctant to implement more complex modelling tools into practical flood inundation modelling studies, unless evidence is provided to establish when such refined modelling tools should be used. The main objective of this study was to determine a general threshold value of the bottom slope that could be used by decision makers as an orientation guide to ascertain when to use a specific type of flood inundation model. The results obtained suggest that in torrential river basins or catchments (i.e., river basins and catchments with a bed slope generally greater than $1 \%$ ), the flood inundation modelling should be conducted by using a flood inundation model that include shock-capturing algorithms in the model solution procedure.
\end{abstract}

Keywords: flood inundation modelling; computational hydraulics; shock-capturing; flood risk; river basins; steep catchments

\section{Introduction}

Flood risk is expected to increase significantly in the future as a result of climate change, an increase in the world's population and intensified urbanisation in flood-prone areas [1-4]. Furthermore, recent flood events in the UK have led to a comprehensive government review of natural flood resilience [5]. The key findings provided by the Met Office have indicated uplifts in extreme rainfall intensity of between $20 \%$ and $30 \%$ for each of the six standard climatological regions of England and Wales over the next 20-30 years. Therefore, there is a growing need for even more accurate flood modelling tools in the future to better manage flood risk.

Two-dimensional (2D) flood inundation modelling is nowadays one of the key components of the majority of flood risk assessment and management strategies. Such 2D hydrodynamic models can be divided into three general categories. These include [6]: (i) models that are based on a simplified version of the 2D shallow water equations, (ii) models that solve the full 2D shallow water equations, and (iii) full hydrodynamic 2D models with shock-capturing ability. A number of studies have focused on benchmarking different types of 2D flood inundation models for a range of various test cases and/or real flood events [6-10]. Such studies have outlined the main differences between 2D models with different complexities, including highlighting the pros and cons of each type of 2D hydrodynamic model, and generally establishing what level of model sophistication is appropriate for modelling various flow conditions.

However, these research findings often do not significantly influence the practitioner flood risk community. This is due to the difference in the perception of flood risks between model developers 
and flood risk practitioners [11-14]. The researchers generally frame flood risk issues using scientific knowledge and expertise. Therefore, they assume that more detailed models will generally lead to more accurate model predictions and thus better decisions can be made [15]. On the other hand, flood risk practitioners generally lack the time and resources to perform complex analyses, or to incorporate the results of complex analyses in their decisions [16]. Therefore, they are often reluctant to adopt more complex modelling procedures (or procedures that they are not familiar with) that are desirable, but which can also increase the complexity of the modelling problem [15].

The main objective of this study was to determine a general threshold value of the bed slope that could be used by regulatory authorities and flood risk practitioners as an orientation guide as to when to use a specific type of flood inundation model. Three different model configurations of the DIVAST-TVD model were considered in this study, including: (i) a configuration that included a shock-capturing capability (i.e., the total variation diminishing (TVD) test case), (ii) a configuration that solved the full 2D shallow water equations (i.e., the MacCormack MAC test case), and (iii) a configuration based on a simplified version of the $2 \mathrm{D}$ shallow water equations, i.e., without the advection terms (i.e., the simplified SI test case). These three model configurations were used to simulate two different events, including: (i) a flood wave propagating along an idealised valley, and (ii) a flash flood event in a short steep river basin in Wales, UK. The results obtained in this study suggest that in a torrential or flashy river basin or catchment (i.e., river basins and catchments with a gradient, or bed slope, generally greater than $1 \%$ ), any flood inundation studies should include shock-capturing algorithms in the model solution procedure. However, this is an orientation threshold value and therefore further research is needed to propose more detailed modelling guidelines.

\section{Study Areas}

\subsection{Idealised Valley}

The idealised valley consisted of a trapezoidal channel (14 $\mathrm{m}$ wide and $1 \mathrm{~m}$ deep) and two adjacent floodplains that were each $100 \mathrm{~m}$ wide. The overall length of the idealised valley was $2000 \mathrm{~m}$, with the valley being divided into two $1000 \mathrm{~m}$ reaches. The upper reach (i.e., the first $1000 \mathrm{~m}$ ) had a different bed slope for each test case, with the bed slope varying from $S=0.001$ to $S=0.1$. For the lower reach (i.e., the second $1000 \mathrm{~m}$ ) the bed slope remained nearly horizontal (i.e., $\mathrm{S}=0.001$ ) for every test case. Finally, there was a $100 \mathrm{~m}$ long and $2 \mathrm{~m}$ deep reservoir at the end of the idealised valley (see Figure 1).

The idea behind the design of this test case was to mimic the propagation of a flash flood in a short and steep river basin. Flash floods generally occur due to a unique and complex combination of meteorological, hydrological and topographical conditions [17]. Intense precipitation is usually considered as the main factor in the generation of flash floods [18]. However, the steepness of the terrain often plays as an important role due to its: (i) orographic effects that augment precipitation, and (ii) promotion of the rapid concentration and propagation of stream flow [19]. Therefore, short and steep river basin valleys or catchments are a characteristic feature of many areas prone to flash flooding, such as much of Wales and the south-east of England in the UK, the Mediterranean region (e.g., Greece, France, Spain), Central Europe (e.g., Slovenia, Slovakia, Austria), etc. [19-21].

The idealised valley computational domain was divided into square cells, with each cell having a plan-form area of $1 \mathrm{~m}^{2}$. An inflow boundary was set as the upstream boundary condition, with a sinusoidal hydrograph being used to represent a flood wave of the form [22]:

$$
Q=q_{p} \sin \left(\frac{\pi}{T} t\right)
$$

where $q_{p}$ is the unit-width peak discharge, $T$ is the duration of flooding and $t$ is the time step. 
(a)

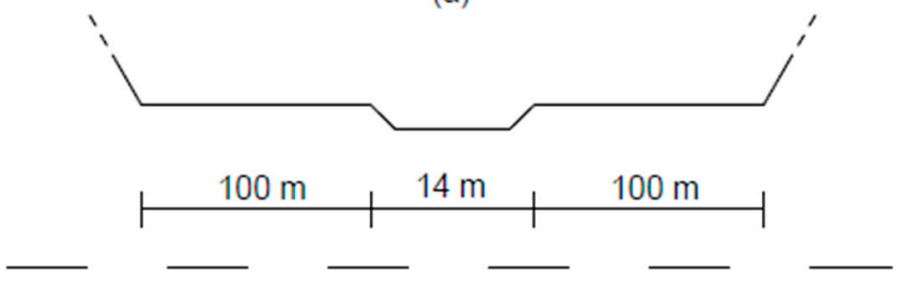

(b)

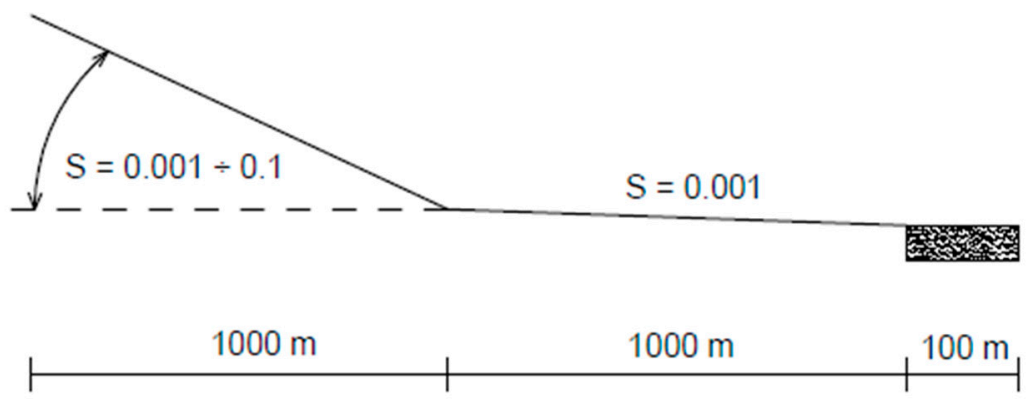

Figure 1. Schematic illustration of the idealised valley, including: (a) the cross-section and (b) the longitudinal section.

In this study, the value of $q_{p}$ was set to $150 \mathrm{~m}^{3} / \mathrm{s}$ and $T$ was set to $4 \mathrm{~h}$. Therefore, the hydrograph used as a boundary input had a relatively high peak discharge (considering the dimensions of the main channel and the valley), a short time-to-peak (i.e., $2 \mathrm{~h}$ ), and the overall flood duration was also generally short (i.e., $4 \mathrm{~h}$ ). The idea behind the construction of this hydrograph was to mimic the general characteristics of an extreme flash flood event $[19,20]$. The downstream boundary was set at the end of the reservoir, and a prescribed water level was specified as the downstream boundary condition. The main channel was assigned a Manning's roughness coefficient of 0.04, while the floodplains were assigned a Manning's roughness coefficient of 0.05 . The selection of these roughness values was based on the roughness parameters applied in the second study case considered in this study.

\subsection{Borth (Wales, UK)}

Borth is a coastal village and holiday seaside resort in west Wales, UK, with many caravan and camping sites located in the surrounding region (see Figure 2a). It is located at the end of the relatively small and generally steep River Leri catchment, which is prone to flash flooding [21]. The most recent flash flood occurred on 9 June 2012, which flooded Borth and the nearby villages of Dol-y-bont and Tal-y-bont. Around 60 properties and tens of caravans were flooded around Borth. Furthermore, a relatively large number of people were evacuated from flooded properties in Tal-y-bont and the caravan sites near Dol-y-bont $[23,24]$. There was a general perception that the 2012 flash flood was one of the severest in history due to extensive media coverage. However, the post-flood study revealed that the magnitude of this flood event was more common than first thought. It was estimated that the return period for this flood event was between 50 and 80 years [21].

The Borth study domain was $9 \mathrm{~km}$ long, $7 \mathrm{~km}$ wide and covered a relatively wide area around Borth, and the villages of Dol-y-bont and Tal-y-bont (see Figure 2b). The $2 \mathrm{~m}$ LiDAR (Light Detection and Ranging) data were used to set up a computational hydraulics model. A rectangular grid was considered in this study, and the computational domain was thus divided into nearly 16 million square cells. The upstream boundary was set as an inflow boundary for the River Leri and the River Ceulan near Tal-y-bont. The estimated peak discharge for the River Leri at Dol-y-bont for the 2012 flash flood was around $80 \mathrm{~m}^{3} / \mathrm{s}$ [21]. However, there were no estimates of the discharges further upstream (i.e., Tal-y-bont) which could be used as inflow boundaries in this study. 
(a)

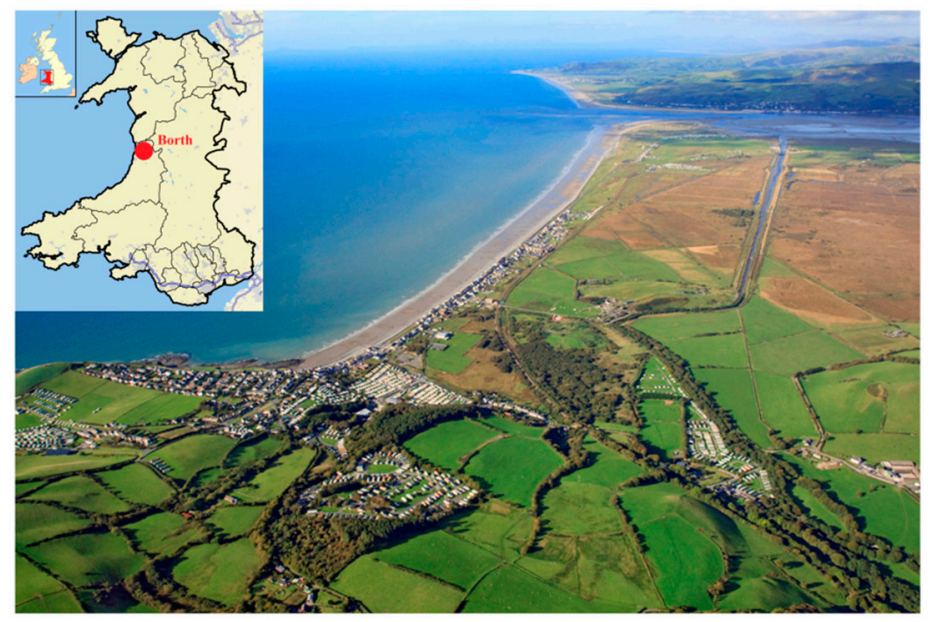

(b)

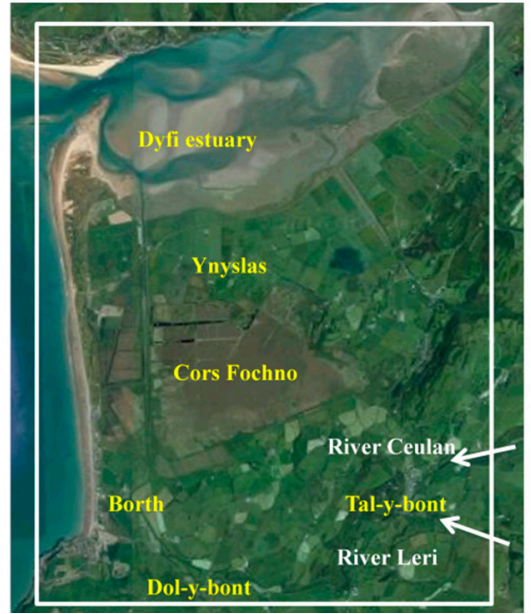

Figure 2. The village of Borth (a) (Retrieved from http:/ / www.janetbaxterphotography.co.uk), and the Borth study domain (b) (adopted from Google Maps).

Therefore, a 1:100-year flood event was simulated in this study, with the estimated peak discharge values for the River Leri and River Ceulan being $64.5 \mathrm{~m}^{3} / \mathrm{s}$ and $19.1 \mathrm{~m}^{3} / \mathrm{s}$. These peak discharge values yield to a similar peak discharge value for the River Leri at Dol-y-bont as it was estimated for the 2012 flash flood. This meant that a general comparison could be made of the flood depths predicted in this study and the flood depths observed/estimated for the 2012 flash flood. The downstream boundary was set in the Dyfi estuary, and a prescribed water level was specified as the downstream boundary condition. The elevation conditions in the Dyfi estuary are governed by the tide. However, there were no reports suggesting that the tide had any effect on the actual flood levels further inland (e.g., around Borth) during the 2012 flash flood. Therefore, it was not deemed to be necessary to include a time-varying tide in the model.

The selection of roughness parameters was based on a site-survey conducted by the authors, and on the roughness values proposed in a previous study conducted for Natural Resources Wales. Based on this survey, the floodplains were assigned a roughness value of 0.05 , while the natural river channel was assigned a roughness value of 0.04 . A post-flood survey was conducted almost immediately after the flood in 2012 by Ceredigion County Council [24]. The aim of the survey was to inspect what damage had been done to hydraulic structures (e.g., culverts and bridges) by the flood. The survey did not find any evidences of damages, blockages or channel obstructions. Therefore, it was assumed that there was no need to specifically model any hydraulic structures in the numerical model (e.g., limited propagation of the flow due to blockage, etc.). However, such an assumption should be made carefully, as hydraulic structures can have an important impact on the flooding phenomenon in the surrounding area, such as during the 2004 Boscastle flash flood [10].

\section{Numerical Model}

The DIVAST-TVD model is a shock-capturing flood inundation model, which was developed by Liang, et al. [25]. This numerical model combines the standard MacCormack scheme with a symmetric five-point total variation diminishing (TVD) term. Total variation diminishing schemes prevent the emergence of numerical oscillations through added non-linear artificial dissipation terms [26]. This makes such schemes applicable to cases that could involve discontinuities in the model solution (e.g., flash floods, dam breaks, etc.). The model is explained briefly below for completeness, while more detailed information about the model development and verifications can be found in the literature $[7,10,25,27-29]$. 
By neglecting the Coriolis, wind and viscous forces, the shallow water equations can be written in the following form:

$$
\begin{gathered}
\frac{\partial \eta}{\partial t}+\frac{\partial q_{x}}{\partial x}+\frac{\partial q_{y}}{\partial y}=0 \\
\frac{\partial q_{x}}{\partial t}+\frac{\partial\left(\frac{\beta q_{x}^{2}}{H}\right)}{\partial x}+\frac{\partial\left(\frac{\beta q_{x} q_{y}}{H}\right)}{\partial y}=-g H \frac{\partial \zeta}{\partial x}-\frac{g q_{x} \sqrt{q_{x}^{2}+q_{y}^{2}}}{H^{2} C^{2}} \\
\frac{\partial q_{y}}{\partial t}+\frac{\partial\left(\frac{\beta q_{x} q_{y}}{H}\right)}{\partial x}+\frac{\partial\left(\frac{\beta q_{y}^{2}}{H}\right)}{\partial y}=-g H \frac{\partial \zeta}{\partial y}-\frac{g q_{y} \sqrt{q_{x}^{2}+q_{y}^{2}}}{H^{2} C^{2}}
\end{gathered}
$$

where $t$ is the time; $\eta$ is the water surface elevation above the still water datum; $q_{x}$ and $q_{y}$ are the discharge per unit width in the $x$ and $y$ directions; $\beta$ is the momentum correction factor for a non-uniform vertical velocity profile; $g$ is gravitational acceleration; $H=h+\eta$ is the total water column depth (where $h$ is the depth below the still water datum); and $C$ is the Chezy roughness coefficient (generally evaluated in terms of a Manning coefficient, where $C=R^{1 / 6} / n$ with $\mathrm{R}$ being the hydraulic radius and $\mathrm{n}$ the Manning roughness coefficient).

The conservative form of the shallow water equations is usually deployed to ensure the conservation of mass and momentum after the discretisation of equations. Following Rogers, et al. [30], Equations (2)-(4) can be rearranged in the following conservative form:

$$
\begin{aligned}
& \frac{\partial X}{\partial t}+\frac{\partial F}{\partial x}+\frac{\partial G}{\partial y}=S+T \\
& \boldsymbol{X}=\left[\begin{array}{c}
\eta \\
q_{x} \\
q_{y}
\end{array}\right], \boldsymbol{F}=\left[\begin{array}{c}
q_{x} \\
\frac{\beta q_{x}^{2}}{h+\eta}+\frac{g \eta^{2}}{2}+g h \eta \\
\frac{\beta q_{x} q_{y}}{h+\eta}
\end{array}\right], \boldsymbol{G}=\left[\begin{array}{c}
q_{y} \\
\frac{\beta q_{x} q_{y}}{h+\eta} \\
\frac{\beta q_{y}^{2}}{h+\eta}+\frac{g \eta^{2}}{2}+g h \eta
\end{array}\right], \\
& \boldsymbol{S}=\left[\begin{array}{c}
0 \\
g \eta \frac{\partial h}{\partial x}-\frac{g q_{x} \sqrt{q_{x}^{2}+q_{y}^{2}}}{(h+\eta)^{2} C^{2}} \\
0
\end{array}\right], \boldsymbol{T}=\left[\begin{array}{c}
0 \\
0 \\
g \eta \frac{\partial h}{\partial y}-\frac{g q_{y} \sqrt{q_{x}^{2}+q_{y}^{2}}}{(h+\eta)^{2} C^{2}}
\end{array}\right]
\end{aligned}
$$

Using the Strang operator-splitting technique [31], the solution to Equation (5) is obtained by solving two one-dimensional problems:

$$
\begin{aligned}
& \frac{\partial X}{\partial t}+\frac{\partial F}{\partial x}=S \\
& \frac{\partial X}{\partial t}+\frac{\partial G}{\partial y}=T
\end{aligned}
$$

For a regular rectangular grid, as used in this study, the explicit discretisation of Equations (7) and (8) can be written as:

$$
\begin{aligned}
& X_{i, j}^{n+1}=L_{x} \boldsymbol{X}_{i, j}^{n} \\
& \boldsymbol{X}_{i, j}^{n+1}=L_{y} \boldsymbol{X}_{i, j}^{n}
\end{aligned}
$$

where $L_{x}$ and $L_{y}$ are the finite-difference operators and the subscript and the superscript for $\boldsymbol{X}$ denote the corresponding grid cell location and time level. 
In the DIVAST-TVD model, the MacCormack TVD scheme is utilised to solve consecutively the two one-dimensional hyperbolic equations at each time step. For example, the discretisation scheme for Equation (9) is given as:

$$
\begin{gathered}
\boldsymbol{X}_{i}^{p}=\boldsymbol{X}_{i}^{n}-\left(\boldsymbol{F}_{i}^{n}-\boldsymbol{F}_{i-1}^{n}\right) \cdot \frac{\Delta t}{\Delta x}+\boldsymbol{S}^{n} \cdot \Delta t \\
\boldsymbol{X}_{i}^{c}=\boldsymbol{X}_{i}^{n}-\left(\boldsymbol{F}_{i+1}^{p}-\boldsymbol{F}_{i}^{p}\right) \cdot \frac{\Delta t}{\Delta x}+\boldsymbol{S}^{p} \cdot \Delta t \\
\boldsymbol{X}_{i}^{n+1}=\frac{1}{2}\left(\boldsymbol{X}_{i}^{p}+\boldsymbol{X}_{i}^{c}\right)+T V D_{i}^{n}
\end{gathered}
$$

where the superscripts $p$ and $c$ denote the predictor and corrector steps; $\Delta x$ is the grid size; $\Delta t$ is the time step; and $T V D_{i}^{n}$ is a TVD term appended to the corrector step of the MacCormack scheme to prevent the emergence of non-physical oscillations near the sharp gradient regions defined as

$$
T V D_{i}^{n}=\left[G\left(r_{i}^{+}\right)+G\left(r_{i+1}^{-}\right)\right] \cdot \Delta \boldsymbol{X}_{i+1 / 2}^{n}-\left[G\left(r_{i-1}^{+}\right)+G\left(r_{i}^{-}\right)\right] \cdot \Delta \boldsymbol{X}_{i-1 / 2}^{n}
$$

where $G$ is a function dependent on the wave speed direction and flux limiter function; and $r$ values are dependent on the gradients around the solution cell.

\section{Methodology}

Different types of flood inundation models would need to be considered in order to reach the main objective of this study. However, one of the major problems when comparing different codes is to enable consistent testing conditions. Different numerical codes can treat some of the key modelling processes differently, such as wetting and drying, implementation of boundary conditions, friction estimation, source terms, etc. This can alter simulation results before different numerical schemes or the level of physical complexity is taken into account [9]. The problem can be avoided by using a single numerical code. Therefore, all simulations within this study were conducted by using different configurations of the DIVAST-TVD flood inundation model. The use of a single code enabled equitable testing conditions, as all simulations were conducted using the same model parameters, such as the same time step, roughness parameters, boundary conditions and numerical scheme.

Three different configurations of the DIVAST-TVD model were considered in this study, including:

- $\quad$ a configuration that included shock-capturing ability (i.e., the TVD test case);

- a configuration that solved the full 2D shallow water equations (i.e., the MAC test case);

- a configuration based on a simplified version of the 2D shallow water equations that excluded the advection terms (i.e., the SI test case).

In the TVD test case, the full shock-capturing ability of the DIVAST-TVD model was included. This meant that the model worked on the principle of solving the full hydrodynamic 2D model with the ability of shock-capturing. In the MAC test case, the shock-capturing ability of the DIVAST-TVD model was excluded, i.e., $T V D_{i}^{n}$ term was excluded (e.g., see Equation (13)). This meant that the model worked on the principle of solving only the full hydrodynamic 2D model. In the SI test case, both the $T V D_{i}^{n}$ term and the advection terms were excluded. Therefore, the model worked on the principle adopted in many reduced complexity and rapid assessment flood inundation models.

This study considered flood events that are characterised by a high Froude number and supercritical flows, and sudden changes in the flow regime (e.g., hydraulic jumps). The application of full hydrodynamic 2D solvers to model such flows often results in unstable model solution and oscillatory results [10]. Even if the model can produce a stable solution, such a solution may not represent properly the conservation of mass and momentum in the regions where sudden changes in in the flow regime occur [32]. The oscillations (or instabilities) in the model solution are caused by the advection terms in the shallow water equations. This being the case, a simple modification was applied to the MAC solution method to improve on the model stability. 
The modification to the MAC solution method was based on the reduction of the value of the momentum correction factor $\beta$ (see Equations (3) and (4)). The momentum correction factor $\beta$ was: (i) reduced to 0.5 when the Froude number was between 0.5 and 0.75 ; (ii) reduced to 0.25 , when the Froude number was between 0.75 and 1 ; and (iii) was set to 0 , when the Froude number was equal or greater than 1 . This simple modification can vastly improve numerical stability as flows become supercritical. However, it also reduces the accuracy of the model predictions due to the reduction in the magnitude of the advection terms. Nonetheless, such modifications are applied in commercial models (e.g., Flood Modeller Pro etc.) and thus widely used by flood risk practitioners.

The main assumption of this study was that as the bed slope becomes steeper and consequently flow characteristics become more volatile, the difference in the model predictions between the three codes considered would increase accordingly. More precisely, it was expected that the model configuration which included shock-capturing ability (i.e., the TVD test case) would be best able to produce generally realistic predictions for steep slopes and consequently rapidly varying flow conditions, whereas the other two model configurations (i.e., the MAC and SI test case) would be less accurate.

\section{Results and Discussion}

\subsection{Idealised Valley Test Case}

Figure 3 shows the maximum water depths as predicted by the TVD, MAC and SI model configurations for different variations of the idealised valley test case. These water depth predictions were recorded in the middle of the floodplains and along the entire length of the idealised valley. In addition, the dashed line in the middle of the each of the smaller figures indicates the boundary between the upper and lower section of the idealised valley, i.e., where the value of the bed slope changed. In addition, all simulations were run on Cardiff University's supercomputer, and were generally completed in less than $15 \mathrm{~min}$.

It can be seen in Figure 3 that there was practically no difference in the model predictions between the three considered model configurations when the value of the bed slope in the upper part of the idealised valley was less than $1.5 \%$. When the value of the bed slope in the upper part of the idealised valley was set to $2 \%$, then the predictions from the MAC and SI configurations started to differ more noticeably from the TVD model configuration. The difference in the water depth predictions between the TVD and the other two model configurations was even more significant with a further increase in the value of the bed slope in the upper part of the idealised valley. This can be readily observed from Table 1, which shows the average difference in the water depth predictions between the MAC and TVD, and SI and TVD test cases expressed in terms of percentage errors.

Table 1. Average difference in water depth predictions between the MAC and TVD, and SI and TVD model configurations for the idealised valley test case expressed in terms of percentage errors.

\begin{tabular}{ccc}
\hline \multirow{2}{*}{ Bed Slope } & \multicolumn{2}{c}{ Average Difference in the Water Depth Prediction } \\
\cline { 2 - 3 } & MAC vs. TVD & SI vs. TVD \\
\hline$S=0.01$ & $1.47 \%$ & $2.62 \%$ \\
$S=0.015$ & $3.72 \%$ & $17.87 \%$ \\
$S=0.02$ & $25.37 \%$ & $87.84 \%$ \\
$S=0.025$ & $75.66 \%$ & $64.25 \%$ \\
$S=0.05$ & $235.10 \%$ & $227.51 \%$ \\
$S=0.1$ & $316.65 \%$ & $509.92 \%$ \\
\hline
\end{tabular}




\section{Water depth comparisons: Idealised valley test}

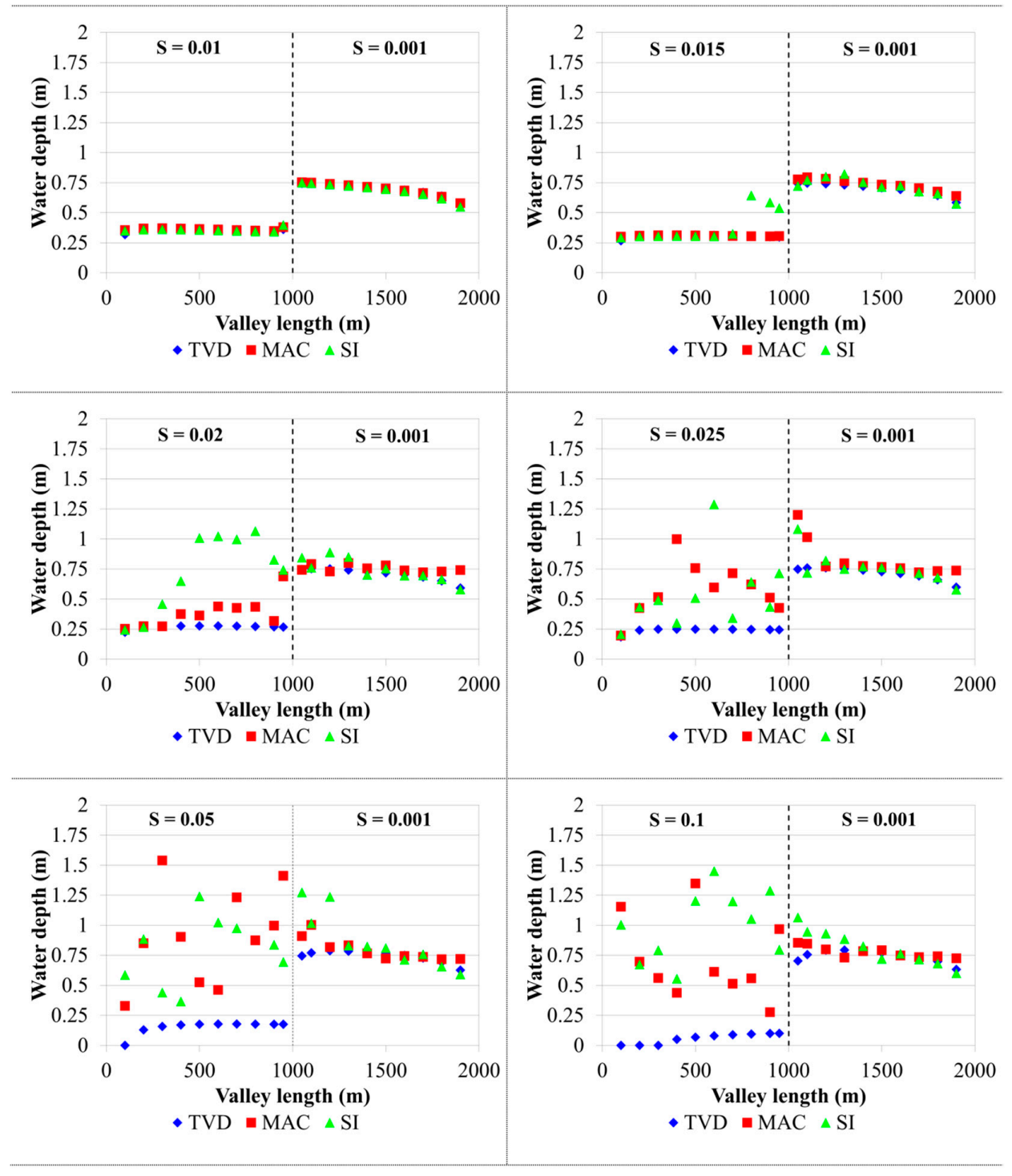

Figure 3. Predicted maximum water depths for the TVD, MAC and SI test cases for different variations of the idealised valley test case.

The results presented in Figure 3 indicate that only shock-capturing (or similar) flood inundation models can produce numerically realistic water depth predictions in steep river basins or catchments. Steep river basins or catchments are often characterised by high velocity and high Froude number flows. These can cause numerical instabilities in the model solution of the simplified 2D and full hydrodynamic 2D models with a conventional solution procedure, and consequently lead to inaccurate model predictions $[6,9,10,33]$. For example, Figure 4 shows the predicted maximum Froude numbers for the different configurations of the idealised valley test case. It can be seen in Figure 4 that Froude numbers in the upper part of the valley became higher with increasing bed slopes. On the other hand, the Froude numbers remained generally the same in the nearly horizontal lower part of the valley for all test cases.

When the predicted maximum Froude numbers in Figure 4 are compared with the results presented in Figure 3, it can be seen that the MAC and SI model configurations predicted much more realistic water depths where the Froude numbers were relatively low. In contrast, the MAC and 
SI model configurations predicted highly unrealistic results in the steeper part of the idealised valley where the Froude numbers were generally high. For this simple case, the obtained results indicate that reduced complexity and full hydrodynamic $2 \mathrm{D}$ models were generally as accurate as shock-capturing flood inundations models when the bed slope was generally less than $1.5 \%$. When the slope was generally greater than $1.5 \%$, only the model configuration that included shock-capturing capability produced numerically realistic water depth predictions.

These results are particularly interesting when one considers how river streams/catchments are generally divided according to the value of the bed slope. In particular, rivers are often defined as having a bed slope that is less than $1 \%$, torrential rivers have a bed slope ranging from 1 to $6 \%$, and finally streams are often referred to as torrents when the bed slope is greater than 6\% [34]. This means that the value of the bed slope that is used to distinguish between a river and a torrential river (i.e., river and torrential catchments) is similar to the value of the bed slope at which the water depth predictions from the considered three model configurations started to differ more significantly.

Furthermore, torrential catchments are small in size (i.e., typically less than $100 \mathrm{~km}^{2}$ ), characterised by a steep terrain and susceptible to the occurrence of sudden, short and violent flood events [34]. However, these are also the characteristic features of catchments prone to flash flooding [19], with shock-capturing flood inundation models already identified as the most appropriate type of flood inundation models for modelling in such areas [10]. All in all, the results obtained for the idealised valley test case suggest that in torrential or flashy river basins and catchments (i.e., where the slope is generally greater than $1 \%$ ), any flood inundation modelling should be undertaken using flood inundations models with a shock-capturing (or similar) capability.

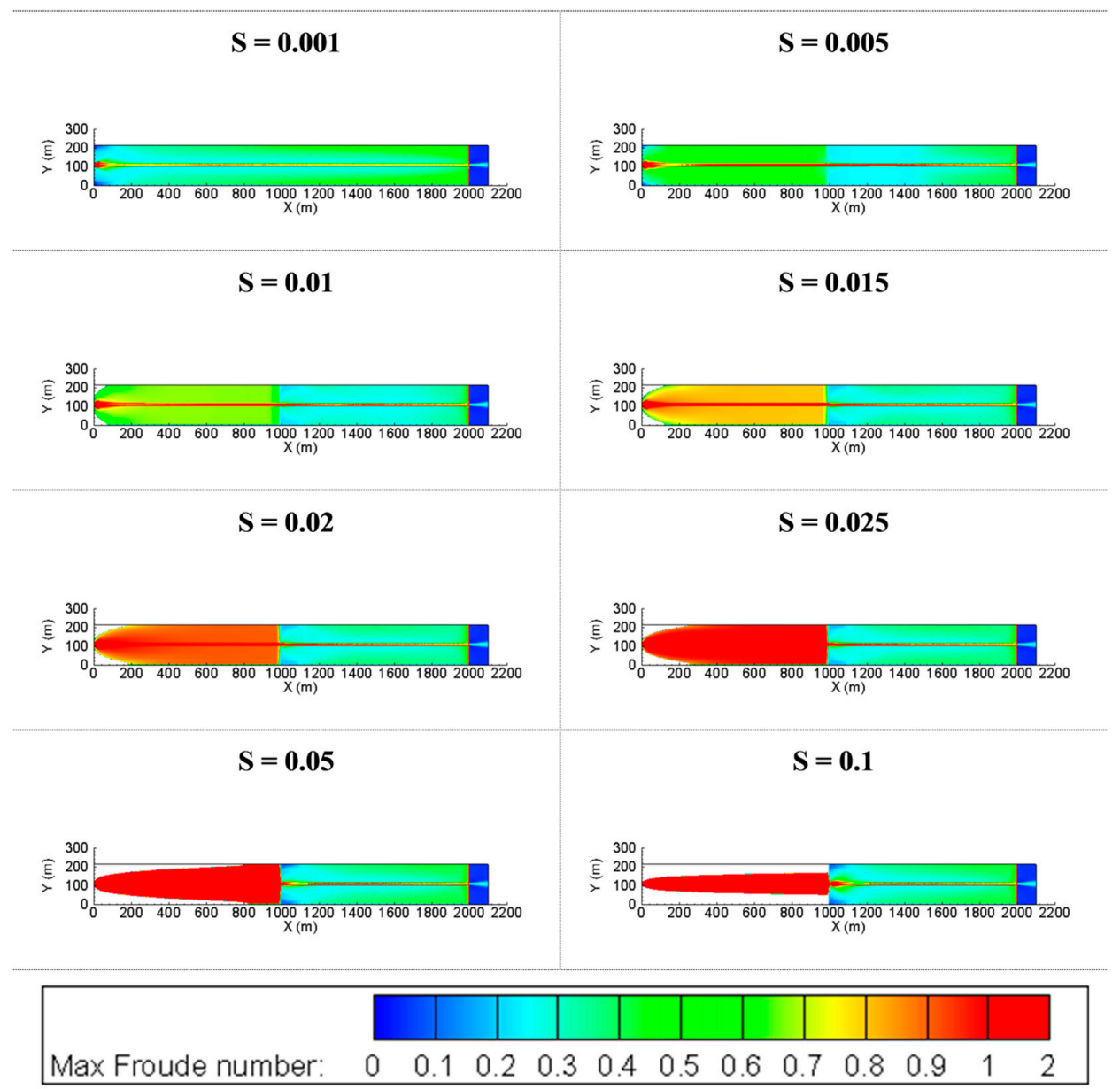

Figure 4. Predicted maximum Froude numbers for different variations of the idealised valley test case. 


\subsection{Flood Inundation Modelling around Borth}

All simulations were run on Cardiff University's supercomputer. The TVD simulation case was completed in seven days, whereas the MAC and SI simulation case were completed in around five days. The predicted maximum water depths from the three considered model configurations were compared at several monitoring points around Tal-y-bont, Dol-y-bont and Borth (see Figure 5). It was possible to estimate the maximum flood levels for the 2012 flash flood for several of these locations due to extensive media reports. These observations/estimations of the actual flood depths for the 2012 River Leri flash flood allowed for some level of validation of the modelling results. The observed/estimated flood levels for the 2012 River Leri flash flood are summarised in Table 2.

Tal-y-bont

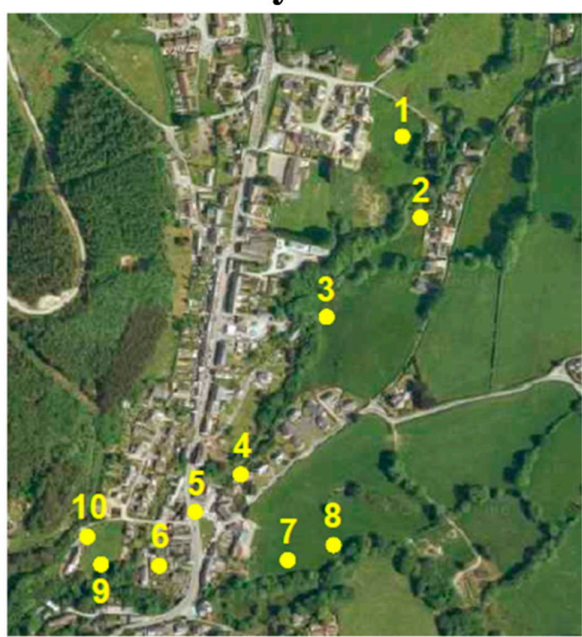

Borth

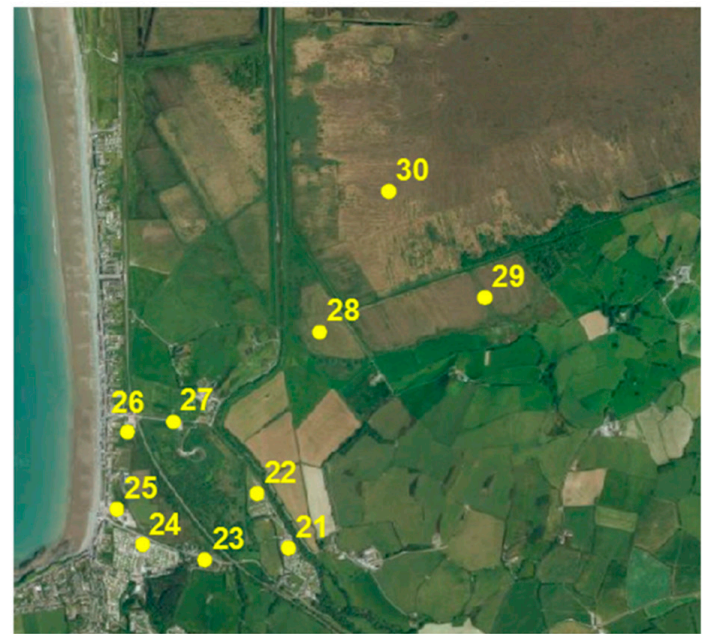

Dol-y-bont

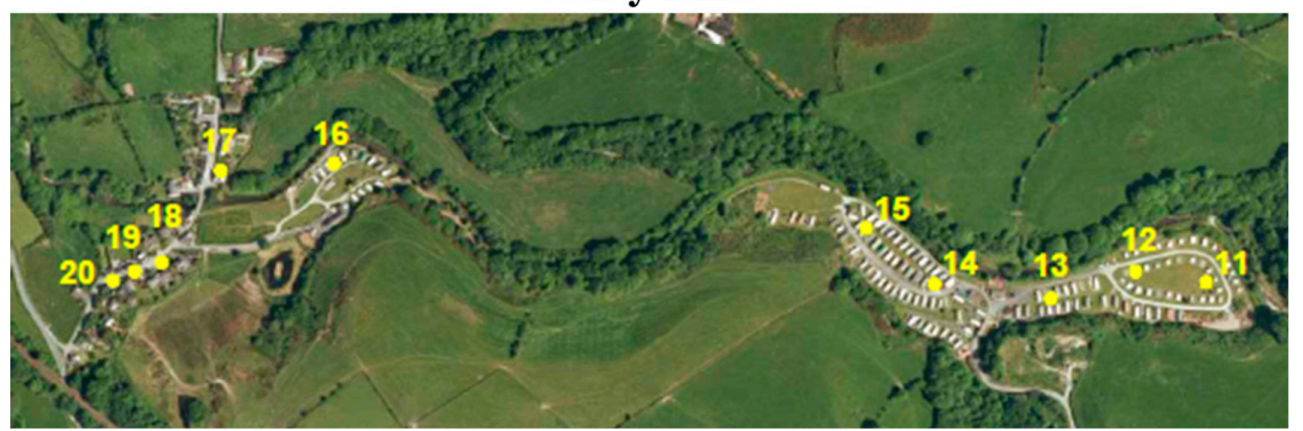

Figure 5. Approximate locations of the selected monitoring points around Tal-y-bont, Dol-y-bont and Borth (adopted from Google maps).

Figure 6 shows the predicted maximum water depths at the selected monitoring points for the TVD, MAC and SI model configurations. It can be seen in Figure 6 that the TVD model configuration matched the observed/estimated flood depth data most accurately, whereas the MAC and SI model configurations were less accurate. This can be more readily observed from Table 3, which shows the difference in water depth predictions between the simulated results and the estimated/observed values for the Borth study case expressed in terms of percentage errors. The greatest difference between the simulated results can be observed in the steepest part of the domain (i.e., Tal-y-bont), while the differences are smaller in the flatter parts of the domain (e.g., Dol-y-bont). As it was shown for the idealised valley test case, steep river basins are often characterised by high velocity and high Froude number flows. Such flow conditions usually cause numerical instabilities in the model solution of simplified 2D and full hydrodynamic 2D models, and consequently result in erroneous model predictions. 
Table 2. The observed/estimated flood levels for the 2012 River Leri flash flood.

\begin{tabular}{ccc}
\hline Monitoring Point & Observed/Estimated Depth & Source \\
\hline 5 & $0.5 \mathrm{~m}$ & Picture [23,35] \\
12 & $1.2 \mathrm{~m}$ & Eye-witness account [23] \\
17 & $1.2 \mathrm{~m}$ & Eye-witness account [36] \\
18 & $0.3 \mathrm{~m}$ & Picture (Retrieved from http://www.alananna.co.uk) \\
19 & $0.3 \mathrm{~m}$ & Picture (Retrieved from http://www.alananna.co.uk) \\
20 & $0.3 \mathrm{~m}$ & Picture (Retrieved from http://www.alananna.co.uk) \\
24 & $0.5 \mathrm{~m}$ & Picture [37] \\
25 & $0.5 \mathrm{~m}$ & Picture [38] \\
27 & $0.3 \mathrm{~m}$ & Picture (Retrieved from http://www.alananna.co.uk) \\
\hline
\end{tabular}

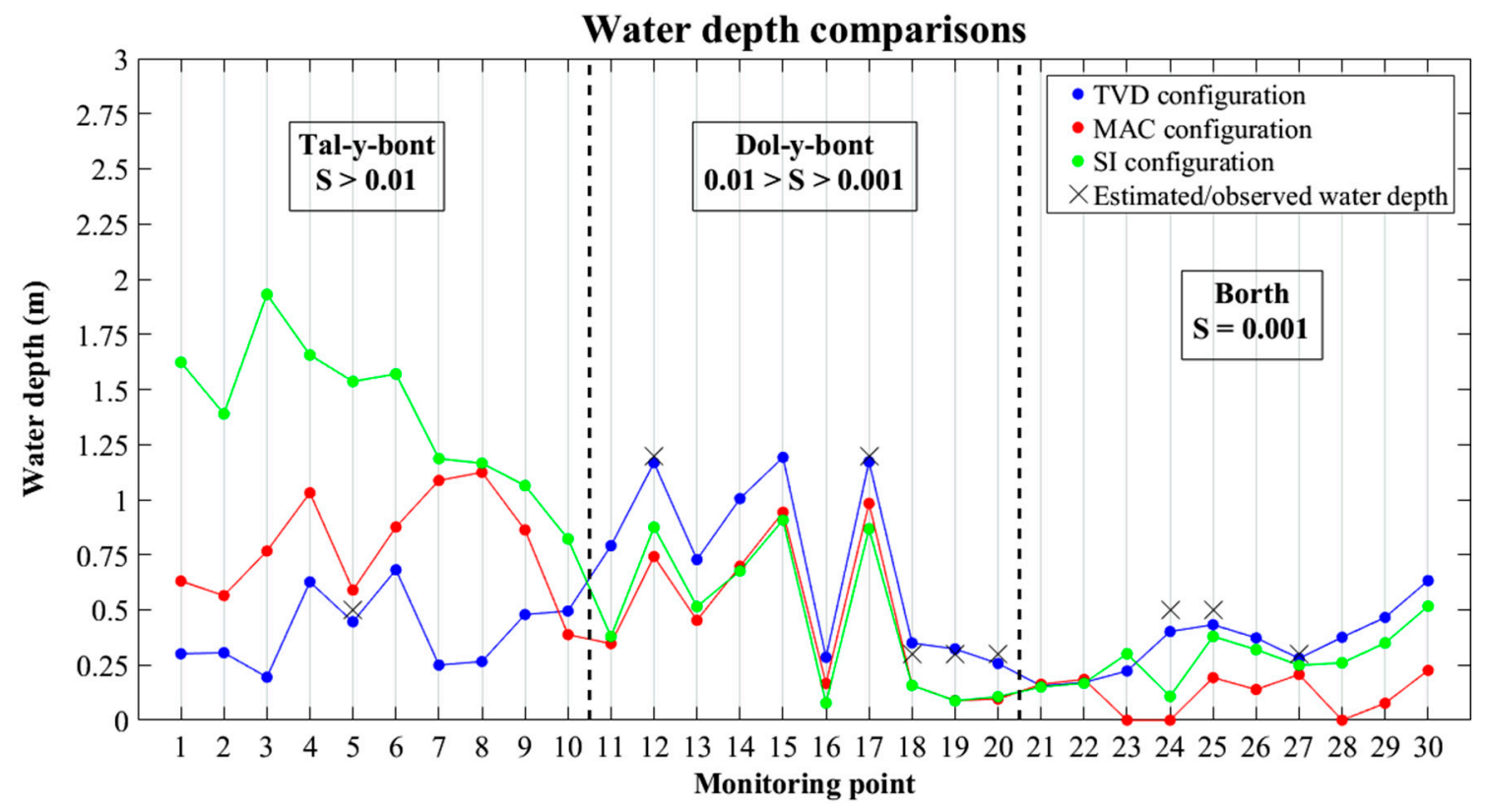

Figure 6. Predicted maximum water depths at the selected monitoring points for the TVD, MAC and SI model configurations.

Table 3. The difference in water depth predictions between the simulated results and the estimated/observed values for the Borth study case expressed in terms of percentage errors.

\begin{tabular}{cccc}
\hline Monitoring Point & TVD & MAC & SI \\
\hline 5 & $10.75 \%$ & $18.10 \%$ & $207.26 \%$ \\
12 & $2.71 \%$ & $38.15 \%$ & $27.05 \%$ \\
17 & $2.32 \%$ & $18.06 \%$ & $27.68 \%$ \\
18 & $16.55 \%$ & $47.43 \%$ & $47.22 \%$ \\
19 & $7.67 \%$ & $70.37 \%$ & $70.80 \%$ \\
20 & $14.45 \%$ & $67.86 \%$ & $64.76 \%$ \\
24 & $19.58 \%$ & $100.00 \%$ & $78.37 \%$ \\
25 & $13.42 \%$ & $61.31 \%$ & $23.96 \%$ \\
27 & $6.83 \%$ & $31.07 \%$ & $16.99 \%$ \\
\hline
\end{tabular}

For example, Figure 7 shows the predicted maximum Froude numbers in the areas around Tal-y-bont, Dol-y-bont and Borth. It can be seen in Figure 7 that the supercritical flow conditions occurred throughout the area around Tal-y-bont. This was as expected since the average value of the bed slope for the River Leri around Tal-y-bont is well above $1 \%$. The volatile flow conditions led to the occurrence of numerical instabilities in the model solution of the MAC and SI model configurations. This resulted in erroneous water depth predictions in the area around Tal-y-bont for the MAC and SI 
model configurations. On the contrary, the TVD model configuration did not experience numerical instabilities due to the shock-capturing capability. Therefore, the TVD configuration produced the most realistic flood depth predictions in the area around Tal-y-bont (see Figure 6).

Figure 7 also shows that the occurrence of supercritical flow conditions was less frequent in the area around Dol-y-bont when compared to the area around Tal-y-bont. This was again as expected since the average value of the bed slope for the River Leri at Dol-y-bont is around $0.6 \%$. Therefore, the flow conditions around Dol-y-bont were less volatile than the flow conditions further upstream around Tal-y-bont. This meant that the MAC and SI model configurations were less susceptible to the emergence of numerical instabilities in the solution procedure. Thus, these two model configurations predicted more realistic flood depths in the area around Dol-y-bont than they did in the area around Tal-y-bont (see Figure 6).
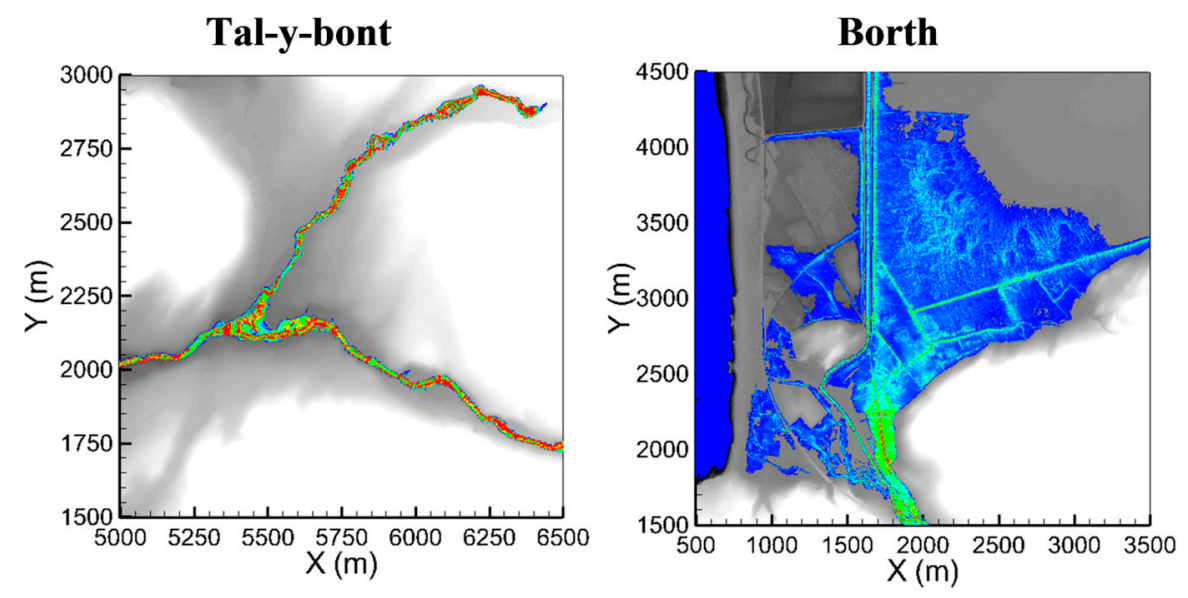

Dol-y-bont

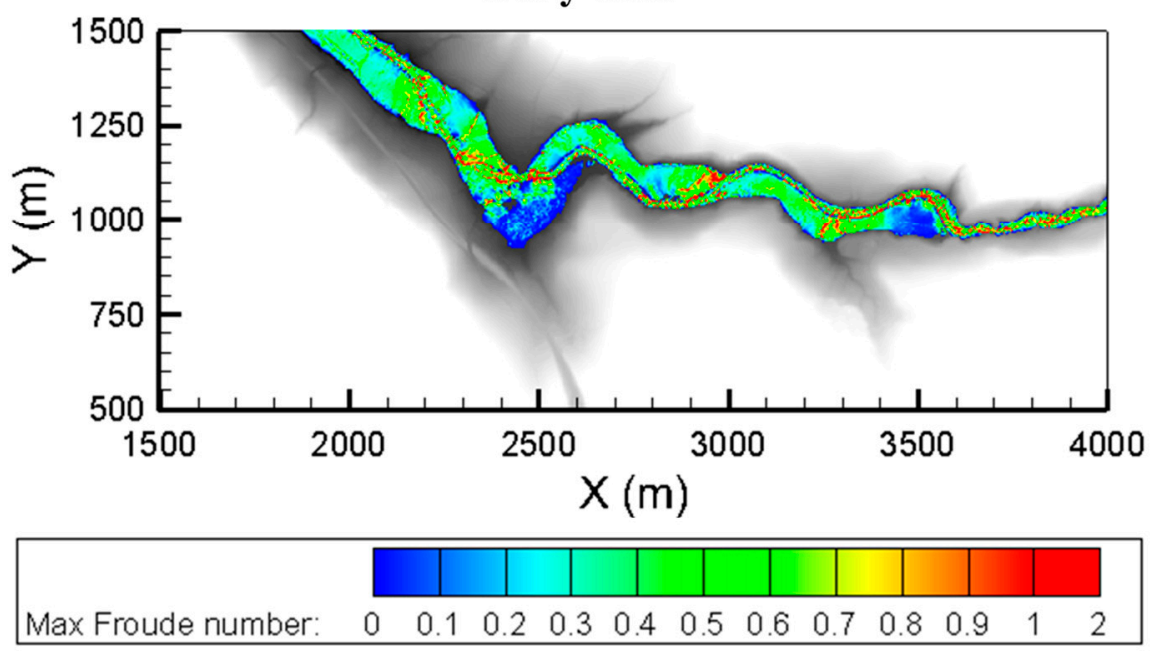

Figure 7. Predicted maximum Froude numbers around Tal-y-bont, Dol-y-bont and Borth.

It can also be seen in Figure 7 that the flow conditions were relatively mild around Borth, with the maximum Froude number generally being less than 0.5. This was also as expected since the terrain around Borth is nearly horizontal. Therefore, it would be reasonable to assume that the difference between the model predictions should be the smallest in this area. For example, Table 4 shows the average difference in the water depth predictions between the MAC and TVD, and SI and TVD test cases at the selected monitoring points in the Borth study domain. It can be again seen in Table 4 that the greatest difference in the model predictions occurred where the gradient was steep and the smallest where the gradient was mild. However, Table 4 also outlines the main differences between 
the simplified and full hydrodynamic 2D solvers when modelling flood events with a high Froude number or supercritical flows.

Table 4. Average difference in water depth predictions between the MAC and TVD, and SI and TVD model configurations at the selected monitoring points in the Borth study domain.

\begin{tabular}{ccc}
\hline \multirow{2}{*}{ Bed Slope } & \multicolumn{2}{c}{ Average Difference in the Water Depth Prediction } \\
\cline { 2 - 3 } & MAC vs. TVD & SI vs. TVD \\
\hline$S>0.01$ & $40.9 \mathrm{~cm}$ & $99.0 \mathrm{~cm}$ \\
$0.01>S>0.001$ & $25.9 \mathrm{~cm}$ & $26.2 \mathrm{~cm}$ \\
$S \approx 0.001$ & $23.6 \mathrm{~cm}$ & $8.7 \mathrm{~cm}$ \\
\hline
\end{tabular}

As discussed earlier, flow conditions were particularly volatile in the steeper parts of the domain (see Figure 7). This meant, for example, that the full 2D hydrodynamic model would have major difficulties in preserving the peak flood wave along the entire modelling reach due to the advection terms. As indicated earlier, advection terms can cause numerical instabilities when full 2D hydrodynamic schemes are used to model high Froude number or supercritical flows. The rise of numerical instabilities generally lead to erroneous predictions in the areas where the gradients are steep (see Figure 6), and usually result in the dissipation of the peak flood wave. This means that such models would thus be prone to under-predict flood levels in the areas further downstream where the gradients are less steep. This course of events can also be observed in this study for the MAC model configuration (e.g., see Figure 6 for the Borth area).

The simplified 2D models (e.g., the SI configuration in this study) generally also have difficulties in preserving the peak flood wave along the entire modelling reach that includes areas characterised by a high Froude number or supercritical flows. For example, the SI model configuration did not include the advection terms, which significantly increased the numerical stability. However, the complete exclusion of advection terms reduces the accuracy of the model predictions. This is particularly evident in areas characterised by a high Froude number or supercritical flows. For example, the SI model configuration greatly over-predicted the peak flood levels in the steepest parts of the domain (e.g., see Figure 6 for the Tal-y-bont area) where the flow conditions were the most volatile (see Figure 7). On the other hand, the SI model configuration predicted (numerically) more accurate flood depths in the flatter parts of the domain (e.g., see Figure 6 for the Borth area). The flow conditions in this area were generally mild (see Figure 7). Thus, decreased physical complexity in the model solution had less of an impact on the accuracy of the SI model predictions.

Simplified and full hydrodynamic 2D models can produce accurate model predictions for flood scenarios that include a high Froude number or supercritical flows, if these flows are not dominant during the simulation process $[9,39]$. For such studies, model instability can be reduced by artificially improving modelling results, e.g., introducing a small patch of high roughness to slow water down in the problematic areas [32]. However, such procedures are not generic and should be applied with caution, because the level of such improvements is based on the modeller's perception of how much fine-tuning is needed [10,32].

Finally, simplified and full hydrodynamic 2D models can produce (to some extent) realistic flood level predictions for rapidly varying flood events, if there exists quality validation data that can be used to fine-tune the models. However, quality validation and calibration data for flood events occurring in steep catchments (e.g., flash floods) are generally scarce [40]. Therefore, the physical and mathematical complexity in the model solution is particularly important for studies conducted in torrential river basins and catchments, because the validation of the modelling results is often impossible. Thus, shock-capturing models are more appropriate for such flood studies, as these models can produce (numerically) accurate predictions for high Froude numbers or supercritical flows without any additional modification or improvements of the modelling procedure. 


\section{Conclusions}

In this paper, we have investigated the threshold value of the bed slope that could stand as an orientation guide as to when to use a specific type of flood inundation model. Three different model configurations of the DIVAST-TVD model were considered in this study: (i) a configuration that included a shock-capturing ability (i.e., the TVD test case); (ii) a configuration that solved the full 2D shallow water equations (i.e., the MAC test case); and (iii) a configuration based on a simplified version of the 2D shallow water equations (i.e., the SI test case). The three considered model configurations were used to model two different flood events, i.e., a flood wave propagating along an idealised valley, and a flash flood event in Wales, UK.

The results obtained indicate that in torrential or flashy river basins or catchments (i.e., river basins and catchments with a stream gradient generally greater than $1 \%$ ) flood inundation modelling should be undertaken using flood inundation models with shock-capturing (or similar) capability. Steep catchments are prone to the occurrence of high Froude numbers and supercritical flows. Such flow conditions usually cause numerical instabilities (e.g., spurious oscillations) in the model solution of simplified 2D and full hydrodynamic 2D models. These instabilities can lead to the dissipation of the peak flood wave and consequently to erroneous model predictions. Even though flood inundation models with shock-capturing (or similar) capabilities are generally more computationally expensive, these models prevent the occurrence of numerical instabilities and thus prevent the dissipation of the flood wave. Therefore, such models can predict (numerically) accurate flood levels for flood events characterised by high Froude numbers or supercritical flows, such as floods occurring in steep river basins and catchments (e.g., flash floods).

This paper proposes an orientation value of the bed slope (i.e., $1 \%$ ) that can be used as a guide as when to use a specific type of flood inundation model. Therefore, further research is needed to develop more detailed modelling guidelines for steep river basins and catchments. Future research will include more rigorous testing conditions and more complex modelling environments. As indicated within this paper, modelling in steep river basins is faced with many difficulties, e.g., a lack of quality data etc. Therefore, future research would also benefit from closer cooperation between academic researchers, regulatory authorities and flood risk practitioners, which would enable more efficient sharing of information, data and practical experience. All these would help in easier development and later implementation of the state-of-the-art modelling techniques to the practical hydro-environmental engineering community.

Acknowledgments: This research project was supported by an Engineering and Physical Sciences Research Council (EPSRC) Impact Acceleration grant. The topographical and hydrological data for the Borth study were provided by Natural Resources Wales (NRW). The contribution of these organisations is gratefully acknowledged. The authors would also like to thank Thomas Green from Advance Research Computing-Cardiff University (ARCCA) for his assistance in using the University's high-performance computing facilities.

Author Contributions: Davor Kvočka was the Research Associate on the project and set-up the model applications and undertook the studies, including assessing the conditions under which shock-capturing algorithms need to be included. Roger A. Falconer and Reza Ahmadian have been leading a wide range of research projects in flood risk modelling and were instrumental in developing the original models. Davor Kvočka drafted the manuscript, which was refined by all authors.

Conflicts of Interest: The authors declare no conflict of interest. The founding sponsors had no role in the design of the study; in the collection, analyses, or interpretation of data; in the writing of the manuscript, and in the decision to publish the results.

\section{References}

1. United Nations (UN). World Urbanizations Prospects: The 2014 Revision; United Nations: New York, NY, USA, 2014.

2. United Nations (UN). World Population Prospects: The 2015 Revision; United Nations: New York, NY, USA, 2015.

3. Güneralp, B.; Güneralp, İ.; Liu, Y. Changing global patterns of urban exposure to flood and drought hazards. Glob. Environ. Chang. 2015, 31, 217-225. [CrossRef] 
4. Muis, S.; Güneralp, B.; Jongman, B.; Aerts, J.C.; Ward, P.J. Flood risk and adaptation strategies under climate change and urban expansion: A probabilistic analysis using global data. Sci. Total Environ. 2015, 538, 445-457. [CrossRef] [PubMed]

5. HM Government. National Flood Resilience Review; HM Government: London, UK, 2016; p. 145.

6. Neelz, S.; Pender, G. Benchmarking the Latest Generation of 2d Hydraulic Modelling Packages; Environment Agency: Bristol, UK, 2013.

7. Hunter, N.; Bates, P.; Neelz, S.; Pender, G.; Villanueva, I.; Wright, N.; Liang, D.; Falconer, R.A.; Lin, B.; Waller, S. Benchmarking 2d Hydraulic Models for Urban Flood Simulations. In Proceedings of the Institution of Civil Engineers-Water Management; Thomas Telford (ICE Publishing): London, UK, 2008; pp. 13-30.

8. Néelz, S.; Pender, G. Benchmarking of 2d Hydraulic Modelling Packages; SC080035/SR2 Environment Agency: Bristol, UK, 2010.

9. Neal, J.; Villanueva, I.; Wright, N.; Willis, T.; Fewtrell, T.; Bates, P. How much physical complexity is needed to model flood inundation? Hydrol. Process. 2012, 26, 2264-2282. [CrossRef]

10. Kvočka, D.; Falconer, R.A.; Bray, M. Appropriate model use for predicting elevations and inundation extent for extreme flood events. Nat. Hazards 2015, 79, 1791-1808. [CrossRef]

11. Faulkner, H.; Parker, D.; Green, C.; Beven, K. Developing a translational discourse to communicate uncertainty in flood risk between science and the practitioner. AMBIO J. Hum. Environ. 2007, 36, 692-704. [CrossRef]

12. Janssen, J.A.; Hoekstra, A.Y.; de Kok, J.-L.; Schielen, R.M. Delineating the model-stakeholder gap: Framing perceptions to analyse the information requirement in river management. Water Resour. Manag. 2009, 23, 1423-1445. [CrossRef]

13. Timmerman, J.; Beinat, E.; Termeer, C.; Cofino, W. A methodology to bridge the water information gap. Water Sci. Technol. 2010, 62, 2419-2426. [CrossRef] [PubMed]

14. Wood, M.; Kovacs, D.; Bostrom, A.; Bridges, T.; Linkov, I. Flood risk management: U.S. army corps of engineers and layperson perceptions. Risk Anal. 2012, 32, 1349-1368. [CrossRef] [PubMed]

15. Leskens, J.; Brugnach, M.; Hoekstra, A.; Schuurmans, W. Why are decisions in flood disaster management so poorly supported by information from flood models? Environ. Model. Softw. 2014, 53, 53-61. [CrossRef]

16. Leskens, J.G.; Kehl, C.; Tutenel, T.; Kol, T.; Haan, G.d.; Stelling, G.; Eisemann, E. An interactive simulation and visualization tool for flood analysis usable for practitioners. Mitig. Adapt. Strateg. Glob. Chang. 2017, 22, 307-324. [CrossRef]

17. Rozalis, S.; Morin, E.; Yair, Y.; Price, C. Flash flood prediction using an uncalibrated hydrological model and radar rainfall data in a mediterranean watershed under changing hydrological conditions. J. Hydrol. 2010, 394, 245-255. [CrossRef]

18. Hill, C.; Verjee, F. Flash Flood Early Warning System Reference Guide 2010; University Corporation for Atmospheric Research: Boulder, CO, USA, 2010.

19. Marchi, L.; Borga, M.; Preciso, E.; Gaume, E. Characterisation of selected extreme flash floods in europe and implications for flood risk management. J. Hydrol. 2010, 394, 118-133. [CrossRef]

20. Gaume, E.; Bain, V.; Bernardara, P.; Newinger, O.; Barbuc, M.; Bateman, A.; Blaškovičová, L.; Blöschl, G.; Borga, M.; Dumitrescu, A.; et al. A compilation of data on european flash floods. J. Hydrol. 2009, 367, 70-78. [CrossRef]

21. Foulds, S.; Brewer, P.; Macklin, M.; Betson, R.; Rassner, S. Causes and Consequences of a Large Summer Storm and Flood in West Wales, 8th-9th June 2012; Fluvio Report No. 2012/01/73; Aberystwyth University: Aberystwyth, UK, 2012; p. 53.

22. Lin, B.; Wicks, J.M.; Falconer, R.A.; Adams, K. Integrating 1d and 2d hydrodynamic models for flood simulation. In Proceedings of the Institution of Civil Engineers-Water Management; ICE Virtual Library (ICE Publishing): London, UK, 2006; Volume 159, pp. 19-25.

23. BBC. Wales Flooding: Major Rescue Continuing Near Aberystwyth. Available online: http:/ /www.bbc.co. uk/news/uk-wales-18378124 (accessed on 1 November 2016).

24. Ceredigion County Council. Flood Investigation Report, North Ceredigion, 8 and 9 June 2012. Available online: http:/ / www.ceredigion.gov.uk/utilities/action/act_download.cfm?mediaid=43372 (accessed on 1 November 2016).

25. Liang, D.; Falconer, R.A.; Lin, B. Comparison between tvd-maccormack and adi-type solvers of the shallow water equations. Adv. Water Resour. 2006, 29, 1833-1845. [CrossRef] 
26. Mingham, C.G.; Causon, D.M.; Ingram, D.; Mingham, C.G.; Causon, D.M.; Ingram, D. A tvd maccormack scheme for transcritical flow. In Proceedings of the Institution of Civil Engineers - Water and Maritime Engineering; ICE Virtual Library (ICE Publishing): London, UK, 2001; Volume 148, pp. 167-175.

27. Liang, D.; Lin, B.; Falconer, R.A. A boundary-fitted numerical model for flood routing with shock-capturing capability. J. Hydrol. 2007, 332, 477-486. [CrossRef]

28. Ahmadian, R.; Falconer, R.A.; Wicks, J. Benchmarking of flood inundation extent using various dynamically linked one- and two-dimensional approaches. J. Flood Risk Manag. 2015. [CrossRef]

29. Kvočka, D.; Falconer, R.A.; Bray, M. Flood hazard assessment for extreme flood events. Nat. Hazards 2016, 84, 1569-1599. [CrossRef]

30. Rogers, B.D.; Borthwick, A.G.; Taylor, P.H. Mathematical balancing of flux gradient and source terms prior to using roe's approximate riemann solver. J. Comput. Phys. 2003, 192, 422-451. [CrossRef]

31. Strang, G. On the construction and comparison of difference schemes. SIAM J. Numer. Anal. 1968, 5, 506-517. [CrossRef]

32. CH2M. Flood Modeller Pro User Manual. Available online: http://help.floodmodeller.com/floodmodeller/ (accessed on 1 November 2016).

33. Ozdemir, H.; Sampson, C.; de Almeida, G.A.; Bates, P. Evaluating scale and roughness effects in urban flood modelling using terrestrial lidar data. Hydrol. Earth Syst. Sci. 2013, 10, 5903-5942. [CrossRef]

34. Ancey, C. Debris flows. In Environmental Geomechanics; Schrefler, B., Delage, P., Eds.; John Wiley \& Sons: Hoboken, NJ, USA, 2013; pp. 1-37.

35. WalesOnline. Lessons to Be Learnt from Ceredigion Floods. Available online: http:/ /www.walesonline.co. uk/news/wales-news/lessons-learnt-ceredigion-floods-6520699 (accessed on 7 December 2016).

36. BBC. Dol-y-Bont Resident Jason Hughes Recalls 'Awful' Flood. Available online: http:/ /www.bbc.co.uk/ news/uk-wales-18391889 (accessed on 11 November 2016).

37. ITV. Floods Overrun Luxury Caravan Park. Available online: http://www.itv.com/news/update/2012-0609/flood-overruns-luxury-caravan-park/ (accessed on 11 November 2016).

38. WalesOnline. Astonishing Pictures and Video of Flooding Rescues from Aberystwyth's Stricken Villages. Available online: http:/ / www.walesonline.co.uk/news/local-news/astonishing-pictures-video-floodingrescues-2052558 (accessed on 17 November 2016).

39. Martins, R.; Leandro, J.; Djordjević, S. A well balanced roe scheme for the local inertial equations with an unstructured mesh. Adv. Water Resour. 2015, 83, 351-363. [CrossRef]

40. Gourley, J.J.; Flamig, Z.L.; Hong, Y.; Howard, K.W. Evaluation of past, present and future tools for radar-based flash-flood prediction in the USA. Hydrol. Sci. J. 2014, 59, 1377-1389. [CrossRef] 